\title{
The Cybersemiotic Model of Communication: An Evolutionary View on the Threshold between Semiosis and Informational Exchange ${ }^{1}$
}

\author{
Søren Brier
}

Department of Economics and Natural Resources, Royal Veterinary and Agricultural University, Rolighedsvej 23, 1958 Frederiksberg C, Denmark; Phone +45 3528 2689, Fax +45 3528 3709, sbr.lpf@cbs.dk

\begin{abstract}
This paper discusses various suggestions for a philosophical framework for a trans-disciplinary information science or a semiotic doctrine. These are: the mechanical materialistic, the pan-informational, the Luhmanian second order cybernetic approach, Peircian biosemiotics and finally the pan-semiotic approach. The limitations of each are analysed. The conclusion is that we will not have to choose between either a cybernetic-informational or a semiotic approach. A combination of a Peircian-based biosemiotics with autopoiesis theory, second order cybernetics and information science is suggested in a five-levelled cybersemiotic framework. The five levels are 1) a level of Firstness, 2) a level of mechanical matter, energy and force as Secondness, 3) a cybernetic and thermodynamic level of information, 4) a level of sign games and 5) a level of conscious language games.

These levels are then used to differentiate levels of information systems, sign and language games in human communication. In our model Maturana and Varela's description of the logic of the living as autopoietic is accepted and expanded with Luhmann's generalization of the concept of autopoiesis, to cover also to psychological and socio-communicative systems. Adding a Peircian concept of semiosis to Luhmann's theory in the framework of biosemiotics enables us to view the interplay of mind and body as a sign play. I have in a previous publication (see list of references) suggested the term "sign play" pertaining to exosemiotics processes between animals in the same species by stretching Wittgenstein's language concept into the animal world of signs.
\end{abstract}

The new concept of intrasemiotics designates the semiosis of the interpenetration between biological and psychological autopoietic systems as Luhmann defines them in his theory. One could therefore view intrasemiotics as the interplay between Lorenz' biological defined motivations and Freud's Id, understood as the psychological aspect of many of the natural drives. In the last years of the development of his theory, Lorenz worked with the idea of how emotional feedback introduced just a little learning through pleasurable feelings into instinctive systems because, as he reasoned, there must be some kind of reward of going through instinctive movements, thus making possible the appetitive searching behaviour for sign stimuli. But he never found an acceptable way of modelling motivation in biological science. I am suggesting a cybersemiotic model to combine these approaches, defining various concepts like thought-semiotics, phenosemiotic and intrasemiotics, combining them with the already known concepts of exosemiotics, ecosemiotics, and endosemiotics into a new view of self-organizing semiotic processes in living systems. Thus a new semiotic level of description is generated, where mind-body interactions can be understood on the same description level.

Keywords: cybersemiotics, cybernetics, semiotics, information, self-organisation

\footnotetext{
The present chapter is reporting work on the conclusion of the Cybersemiotic project and its final model. The article is an integra tion and further development of three articles. The first article entitled "Cybersemiotics and the question of informational and semi otic thresholds" was presented at the International Colloquium on the Semiotic Threshold from Nature to Culture, organized by Winfried Nöth and held at The University of Kassel, Germany, February 16-17, 2001. The article is now accepted for publication by World Future. The second article "Intrasemiotics and Cybersemiotics" was submitted for the proceedings of the fist Biosemiotic Gatherings in Copenhagen 2001 and has been published in Sign System Studies 30.1:113-127. 2002. Finally I recently published the article "Luhamm Semioticized" in the Journal of Sociocybernetis, Vol. 3, no. 2, 2002/2003, pp. 13-22, to which most of the figures were developed. In the presesent article, the general discussing of a scientific world view for information combined with the Cybersemiotic model of cognition and communication is presented in an overview. For more detailed analysis and discussions, I refer to my papers listed in the reference list. These have all been collected and rewritten into a book manuscript called The $C y$ bersemiotic Framework, which is now being processed.
} 


\section{Introduction}

What are information, cognition, meaning, intelligence, mind and communication? How did mind emerge out of natural evolution? What is the difference between animal, human and machine intelligence and communication? What is the difference between physical and informational interaction? And, further, between the informational and the semiotic (sign level) and again language interactions. What and where are the thresholds?

This article deals with the threshold problem in semiotics and information science in the broader context of the attempts to make general scientific theories of information, cognition and communication as we see, for instance, in the cognitive sciences' information processing paradigm (Brier 1992). The foundation of information science international transdisciplinary group (FIS) has for more than ten years discussed posible ways of making a broad philosophical framework to understand basic concepts in a transdisciplinary in formation science. I am one of the few biosemioticians in this group.

The purpose of these transdisciplinary theories is to help us frame the problems of understanding manmachine interface, intelligence and linguistic interaction amongst other things by clearing up the epistemological problems of the difference between how digital machines work, and how living systems perceive, think and communicate. Furthermore, it is to find out what the physical, chemical, biological, psychological, and social foundations of communication are.

I want to discuss the question of threshold in a broader epistemological and ontological context of the metaphysics of knowledge systems and further in a philosophy of science context, taking into considera tion Peircian semiotics, cybernetics and information science (Brier 2000a,b,c). The relation and conflict between informational and semiotic approaches comes into focus in this context. As we shall see later, the semiotic threshold discussion is very similar to the problem of whether objective information exists in nature, as required by the pan-informational paradigm.

I view the threshold discussion as situated at the crossroad of the scientific worldview and its cybernetic theory of information, general epistemology, the bio-psychological theory of cognition and semiotic theory of signification. It is a most interesting point where our conception of nature/reality, cognition, communica tion and the nature of knowledge, and our understanding of the human mind and the relation of mind to matter are all involved at the same time. The threshold discussion has also been going on for some time within the context of the informational paradigm (Ruech/Bateson 1987: 67). Both the informational and the Peircian semiotic paradigms are transdisciplinary paradigms (Deely 1990) suggesting solutions to our scientific problems of making a unified theory of nature, cognition and mind. This is contrary to the traditional mechanistic scientific paradigm, where the concept of mind as inner life has to be outside of the theory.

In their pan-version (everything is information or everything is signs) they both suggest that the connection between mind and nature is either informational or semiotic, which are in our mind as well as in nature. The pan-views make radical changes in our conceptions of both mind and nature

1. The informational paradigm makes nature full of information and understands our mind as a computer. But it cannot encompass a theory of meaning and signification.

2. The semiotic paradigm makes all nature signs but tends to deplete the living of any special significative abilities, and it tends to remove the idea of an independent reality from physical nature.

On the other hand, the original mechanistic framework of classical physics did not encompass concepts of information and meaningful signs at all. In previous papers I have pointed out how pan-informational and pan-semiotic paradigms seem to compete in covering the same subject area with a new transdisciplinary framework (Brier 1992, 1999a, 2000a), each with specific advantages and drawbacks. I have attempted to develop a non-reductionistic framework encompassing them both called Cybersemiotics (Brier 1995, 1998 $a, b)$. This approach tries to deal with the profound epistemological problems whose importance phe nomenological philosophy (Kirkeby 1997) has shown. By working it out, an attempt to make a framework 
for studies of human cognition, understanding and language is launched, which at the same time attempts to state the prerequisites for any scientific endeavour as such (Brier 2000d). Peircian semiotics, with its blend of phenomenology and pragmatics, is therefore one of its foundations.

On this basis, I want to show how Cybersemiotics, through a series of models, can describe the differ ences and continuity between inanimate and animate systems, between living and socio-linguistic systems, and between those and mechanical and cybernetic informational digital systems (mostly machines).

\section{Previous Paradigms of Mater, Mind and Meaning}

To clarify the problems, let us start by analysing paradigms that attempt to explain the whole area from the foundation of nature to human intelligence, consciousness and communication, or put in another way, explaining from the laws of nature to the meaning of humans in culture. I will then discuss the limitations of such enterprises in general. Then I will look at the shortcomings of every paradigm. I will then construct a coherent framework, building on the viable parts of each (cybersemiotics). Finally, I will present a model of the prerequisites for human communication, concentrating on the informational, semiotic and linguistic as pects of embodied human communications.

At present, I can see six basic significant models within science trying to cover the whole range, from the basic patterns, laws and forces of inanimate nature to the phenomena of life and consciousness within one paradigm and a few all-encompassing basic concepts

1. The mechanical materialistic metaphysics that refuses to talk about information and signs in nature including animals. It often presumes that the phenomenon of thinking in meaningful signs, within hur mans, is not connected to consciousness or sometimes not even to intentionality. These understandings are often grounded in the view that these phenomena are illusory (eliminative materialism) [references, e.g., Rorty, Paul Churchland]. This means that they do not consider intentionality, free will and consciousness to have any real causal effects on things in the physical/real world, including our own bodies. The difference between the physical, the chemical and the biological level of reality is only seen as a consequence of organisational levels.

2. Pan-informational metaphysics where information is seen as an objective part of all nature and culture like matter and energy. Already in 1929 Szilard suggested a converse relationship between information and entropy, referring to Boltzmann's thermodynamics, or statistical mechanics. Shannon and Weaver (1949), in fact, referred to entropy in their own work as well, mainly because of similarities with the equations that dealt with statistical events - equations originally written to describe the outcomes of games of chance. But it was Norbert Wiener (1961) who took the full step and declared that informa tion not only is not matter or energy, but that thermodynamic entropy is the opposite of the statistical concept of information (Brier 1992) defined as neg-entropy. This approach was supported by Schrödinger (1967) in his book from 1942 What is life? (which places him before Wiener, Shannon and Weaver) and later by Ruesch and Bateson (1987, org. 1967), carried into Bateson's (1973) Steps to an Ecology of Mind, and further developed by Tom Stonier (Stonier 1997) just to mention a few important figures. The result of all this was that information came to be viewed as the opposite of en tropy. Information could be understood as constructing order in the face of disorder. Prigogine's (Prigogine/Stengers 1984) self-organizing, dissipative structures can be seen as gathering not only organized energy, but information, and simultaneously dissipating energy and making entropy grow.

Thus, the concepts of energy, order, and information, on the one hand, and entropy, disorder, and loss of information on the other, became connected in such a way that we perceive information as having something to do with patterned organization and the reduction of uncertainty (Combs/Brier 2001). Informa tion is then seen as the organizational aspect of nature. Stonier (1997) even talks about "the infon" as a 
basic constituent of nature, much like MacKay (1969) SAW "the logon" as the unit of destruction in the physical case ${ }^{2}$.

This approach is most often developed within a first order cybernetics metaphysics, which sees the world coming into being as a self-organized system consisting of other self-organized systems. For Wiener and Bateson the breakthrough was to unite the theory of information with the Bolzmanian interpretation of thermodynamics and thereby overcoming the Cartesian duality of mind and matter, but they did not manage to develop this into a full-fledged metaphysics.

Many other cyberneticians working with this general model clearly take inspiration from Bertallanffy's General Systems Theory. Here the anti-dualistic view is based on an organismic evolutionary worldview including a theory of emergence and holism with a belief in some kind of continuity between mind and matter that is quite close to Peirce's, but lacking his triadic philosophy. This metaphysical aspect seems to be overlooked by many modern theorists, such as Stonier, but not by Jantsch (1980), Lazslo (1995) and Goerner (1993), where a new kind of eco-system-spiritualism or objective idealism seems to be developed as a holistic interpretation of the modern scientific results in Cosmology and quantum field theory. But how can such a notion dealing with the creation of form say anything interesting about the nature of discourse?

3. The Luhmannian second order cybernetics approach where nature is seen as a source of enumerable differences. Here the cybernetic system decides which difference should make a difference and become information in the organism and its social communication in the human society. Somehow there is a situation in which a cybernetic autopoietic system makes the first distinction by making a difference between the system and its surroundings. Luhmann (1995) never explicates the nature of this Firstness before the first distinction as Peirce does or as phenomenologists like Heidegger and Blanchot'$s$ work with. Still, his idea is originally based on Spencer-Brown, who seems to work with a Buddhist inspired theory of the Void or Emptiness, which seemingly contains the potentiality of both mind and matter. But this aspect seems to be lost in Luhmann's theory. Inspired by Husserl, Luhmann embraces concepts of intentionality and meaning, but in a Hegelian kind of functionalism minus the spirit. This paradigm, in my view then, is close to the Peircian semiotic view except that it does not have a cor lapsed triadic theory of the sign vehicle and lacks a developed theory about the biological systems' contribution to the generation of meaning (Brier 1999b).

4. Peircian (bio)-semiotics is specific from other semiotic paradigms in that it not only deals with intentional signs of communication but also encompasses non-intentional signs such as symptoms of the body and patterns of in-animate nature. It then encompasses both nature and culture. Peircian semiotics breaks with the traditional dualistic epistemological problem of first order science by framing its basic concept of cognition: - Signification - on a triadic semiotic philosophy. The triadic semiotics is integrated with a theory of continuity between mind and matter (Synechism) where the basic three categories (Firstness, Secondness and Thirdness) are not only inside the perceiver's mind, but also in the nature perceived. This is connected to the second important ontological belief in Peirce's philosophy, namely Tychism that sees chance or chaos as basic characteristics of Firstness. This is finally combined with an evolutionary theory of mind (Agapism) where mind has a tendency to take habits in nature. Chaos or chance is seen as a First, which is not to be explained further (for instance by regularities). It is the basis of habit taking and evolution. The chaos of Firstness is not seen as the lack of law as in mechanicism and rationalism, but as something full of potential qualities to be manifested in dividually in Secondness and as general habits and knowledge in the dynamic objects and semiosis in Thirdness (Peirce 1992). This is the deep foundation of Peirce's pragmatism. With chaos as spontaneity at the foundation no laws will in reality be exact. There will always prevail a little spontaneity on both the level of Secondness and Thirdness. As a result of the initiative and work of Thomas Sebeok (1976, 1989), Peirce's semiotics is now interpreted as covering all living signifying systems in a biose miotic approach.

\footnotetext{
2 Thanks to John Collier for pointing out MacKay to me and for his most valuable critique of an earlier version of the manuscript.
} 
In the biosemiotic interpretation based on the Peircian triadic semiotic philosophy, semiosis thus works on a triadic basis in an evolutionary and pragmatic view. The unmanifest Firstness is seen as chaos of qualia, basic form and feeling with a tendency to take habits, which manifests through Secondness and Thirdness. Matter is seen as "effete mind". Matter and mind are united in the continuum of Firstness and develop through "Evolutionary love" into Secondness' manifestations of resistance, force, dualistic concreteness and impenetrability of objects. Secondness provides constraints on perception and cognition in the Thirdness of true triadic sign processes. The term, quasi-semiotic objects then recognizes systems in nature and culture, working with differences, often in a form of coding, instead of physical causality on one hand and meaningful semiosis on the other. In nature, we are in this context dealing with systems of Secondness that have established an information level above the energetic and causal level of nature. The area, thus delimited from true semiosis, is part of what classical first order cybernetics considered its subject area: goal oriented machines and pattern forming self-organized processes in nature based on information. Still the exact role of the living systems in establishing true semiosis is not very clear in Peirce's the ory and neither is the description of the special biological qualities that make this happen. According to Santaella Braga (1999), Peirce was on the track though recognizing chance-spontaneity in the nerve cells as "the outward aspect of that which within itself is feeling" (Peirce CP 6. 265).

The pan-semiotic metaphysics claims further that all environmental phenomena are ultimately semiotic in their essence. The universe is perfused with signs as the famous quote from Peirce goes. Peirce's three categories are universal. Semiosis is everywhere; either because everything is semiosis in its nature or be cause the only way we can know anything is through semiosis. The latter is a pan-semiotic constructivism encompassing both culture and nature. The construction of reality is done by the human societies through living together in language. This kind of bio-social constructivism takes this approach very close to Maturana'$\mathrm{s}$ bio-constructivist development of the autopoiesis theory from a cybernetic perspective. Thus it is close to becoming a human-centred metaphysics (a subjective idealism) with no explicit idea of what nature could be in itself or, to put it another way, what kind of external source there could be for the signs of nature.

The other version is the modern version of pan-semiotics claiming that signs are as real as atoms and energy, actually that latter are also signs. These signs grow by themselves as made clear in Merrell's book (1996): Signs grow; Semiosis of life processes. Reading Merrell, and Emmeche's (2000) critique of him, it is clear that Merrell is viewing signs as independent living beings growing by themselves. The pansemiotic interpretation takes Peirce's statements of teleonomy in causality and that the universe is perfused with signs to mean that whenever there is Thirdness there is semiosis. Then there is also semiosis in inanimate nature. Physio-semiotics, as Deely $(1992,1997,1998,2001)$ calls it, suggests that semiosis is the core of evolution. This means that although there are physical laws so rigid that they are almost pure Secondness, in most laws in evolving nature there is a basic telonomy, which has existed throughout evolution. Here classical physical laws are seen as universal, exact, and deterministic. Thermodynamic laws are by some (Prigogine/Stengers 1984) accepted as genuine statistical and biological "laws" much more teleonomic and semiotic in nature. The fundamental question is if Thirdness really has to bee seen as physiosemiosis?

Most modern versions of pan-semiotics is an interpretation of C.S. Peirce's semiotics, as he is the only philosophic semiotician to include natural signs in his theory. One way to perceive the consequences of his triadic metaphysics and his broad theory of mind, when placed in his theory of continuity (synechism) and evolution, is to accept physiosemiosis, which John Deeley (op. cit.) was the first to do. This kind of realistic (objective idealistic) semiotic metaphysics certainly makes the emergence of life and mind through self-organized new complexities of semiosis much easier to accept but also raises new threshold problems. We will have to define the qualitative differences between physiosemiosis, phytosemiosis, zoosemiosis and antrophosemiosis. Biosemiotics has so far only wanted to encompass the last three of them. There are some profound similarities between Peircian pansemiotics and the organismic view of Bertalanffy's general sys tem theory that also refused mechanism as a possible basis for a scientific theory of evolution. Prigogine's work and his fierce debate with mainstream mechanicists has shown that this is a central problem. The difference between the biosemiotic interpretation and a pan-semiotic one is that the biosemiotic interpretation 
is limiting the ability of true semiosis to living systems. Biosemiotics considers machine processes and pat tern/signal interaction in nature only as quasi-semiotic (not true triadic) processes.

As we can see from the short descriptions of the five basic views above then the central distinction to be discussed are the threshold between living and "dead" nature, and between living and mechanical systems, such as computers, and further the difference between information and meaning. Another important part of this discussion will be between the modern scientific approaches that deal with meaning and the phenomenological part of reality on the one hand, and on the other to deal with the demands on science to deliver true explanations of an independent reality. This demand has increased ever since our religious and mythical frameworks were challenged by the world view of the classical mechanical sciences, the ra tionality and historical thinking of the Enlightenment, Darwinian evolution, the psychology of modernity and finally the linguistic turn. It seems to place truth and meaning in opposite camps. Let me therefore start with a short history and philosophy of science perspective (based on Brier 2000d) on this matter.

\section{The Explanatory Quest of the Sciences since Religion Lost Power}

Ever since Galileo, through experiments and theories of an earthly science combined with his enforce ment of Copernicus' view of the heavens, confronted the Catholic Church's worldview, religion as the upholder of a meaningful world has been challenged. The evolution of classical (mechanical) physical science and its concept of universal mechanical natural laws were some of the most important instruments to break the Church's worldview and our view of our own place in it. The worldview of the Catholic Church was one of the core foundations of the culturally produced meaningfulness of the individual's personal life. It told us where we came from, where we could go and the meaning of our lives.

Further, since the philosophers of the Enlightenment and later Marx and Engels broke the view of the social order as "heavenly sent", a further disturbance in our belief in that everything in our social order was "as it should be" was created. Darwin destroyed our belief in man coming from a higher and meaningful place and thus being endowed with a meaningful destiny, accordingly. He partly destroyed the idea of the human soul as descended into our body from the "divine above". Freud spoiled our idea of being perfectly conscious and rational beings in control of our language and ourselves and own drives. Nietzsche finally declared God "dead", and he and other philosophers left us in a nihilistic vacuum with no universal meaning and values left.

Since then man has increasingly looked to science for new explanatory stories of himself. It has lead to what llya Prigogine and Elisabeth Stengers called "World Formula Thinking"; the belief that final explana tions can be found through science, especially through algorithmic approaches such as in artificial intelli gence, the search for "the algorithms of the book of life" in the genes and in the Grand unification theories of physics, the last attempt of which was the super string theory (Brier 2000d).

Descartes' dualism attempted to save the human soul from the mechanistic grip of science, but his own followers' experiments with brain lesions in doves and the later reflexiological view in brain and behavioural science, further developed with learning theories of "conditioning" by behaviourism, entrenched the human mind and behaviour into the scientific subject area.

Cybernetics, information theory and science, plus the theory of artificial intelligence, have produced functionalistic approaches of our understanding of cognition and communication (Brier 1992). These approaches are now combined in the transdisciplinary program of the information-processing paradigm of cognitive science. It is promoting a paradigm of cognition as a software program based on algorithms in the brain's neurological hardware (Brier 2000, d). At the same time quantum mechanical field theories get more attention as possible tools to explain the continuum character of consciousness (Penrose 1995).

Through science we have also learned to be sceptical towards systems that tend to explain too much. Such systems are religious, mythical-magical or ideological-political systems of belief and power. Still by the end of the $20^{\text {th }}$ century modern science encompasses attempts to combine evolutionary, historical and developmental theories of the environment, the living systems, individual conscience and socio-cultural lin- 
guistic meaning and values into one big scientific narrative, completely ignoring the post modernistic warnings against the deceptiveness of grand narratives.

These stories are Grand Evolutionary Theories (GET) wanting to combine Big Bang cosmology of the self-organization of energy and matter, and the evolution theory of the living. Modern science attempts to explain life from physics and chemistry by computational A-life simulations, and through manipulating genes and other chemicals. The final proof of such a theory could be the artificial construction of life through an independent synthesis of macromolecules and a combination of them, creating the organelles within artificially created membranes producing a living cell. This is being planned as I write.

As we in the sciences expect to explain matter as a specific form or organization of energy, matter is then expected to provide the foundation for an explanation of life as a unique organization of matter. The grand evolutionary story attempts to explain them all in one story starting with energy from a quantum va cuum field turning into matter, time and space. By process of self-organization information and life is supposed to emerge, and later again central nervous systems, social organization, semiosis, communication, language, culture and consciousness.

Modern Big Bang cosmology combined with unified field and super string theory delivers the materialist ic story about the reality we inhabit, which we now call the Universe. It also tells the story about the evolut tion from radiation to subatomic particles, further how the atoms of the basic chemical elements were created through "cooking in the stars" and supernova's explosions, and finally the creation of the multitude of molecules, climaxing in the macromolecules that are the essential chemical components of living systems. This is then often combined with theories of objective information, which perceive energy as self-organizing into patterns and systems of matter in the expanding universe and further on to living systems, cognitive systems, linguistic and conscious systems in culture. Often this story is combined with Richard Dawkins' theory of the selfish gene, and of culture as a collection of selfish memes (Dawkins 1989, Blackmore 2000). Growing up in a culture, the child's mind is infected with the memes of culture and its worldviews. They program its mind with unitary ideas and causalities. This explanatory narrative of reality and meaning is most often performed through religion in the pre-scientific and its pre-industrial societies, but in the modern industrialized cultures, the scientific rationality and worldview is more and more taking over.

I have here in a very general way outlined the character of these explanations. But I doubt:

1. That such a grand story is scientifically possible.

2. That it is the true nature of science to construct this type of explanation.

3. That we will ever be able to provide in generally accepted shared language, universal explanations that combine the four basic constituents of human existence (energy/matter, embodied life, language and conscious inner life) in one discourse.

I suggest that natural science, social science, arts and humanities, practical sciences, philosophy and any other systematic search for public knowledge starting with: 1. Embodiment: our body is at least a main source of life and cognition. 2. Consciousness: consciousness is the source of an inner life of cognition, volition, feeling and perceptual qualities (qualia). 3. Situated in meaning: In semiosis meaning is constructed through language in a social and cultural network of other living, linguistic conscious systems. 4. Relat ively autonomous environment: Placed in an environment that seems partly independent of our perception and being (Brier 2000d). See figure 1.

As analysed above, humans are embodied, feeling and knowing cultural beings in language. My point then is that this makes us live in four different worlds

1. Embodiment: Our body hood and our sharing of body hood with other living species.

2. Inner Mental World: Our inner world of emotions and thoughts manifesting as mind and conscious ness.

3. Physical nature: The physico-chemical aspect of ourselves and of the environment of the natural world. 
4. Culture: The cultural world of language and meaning.

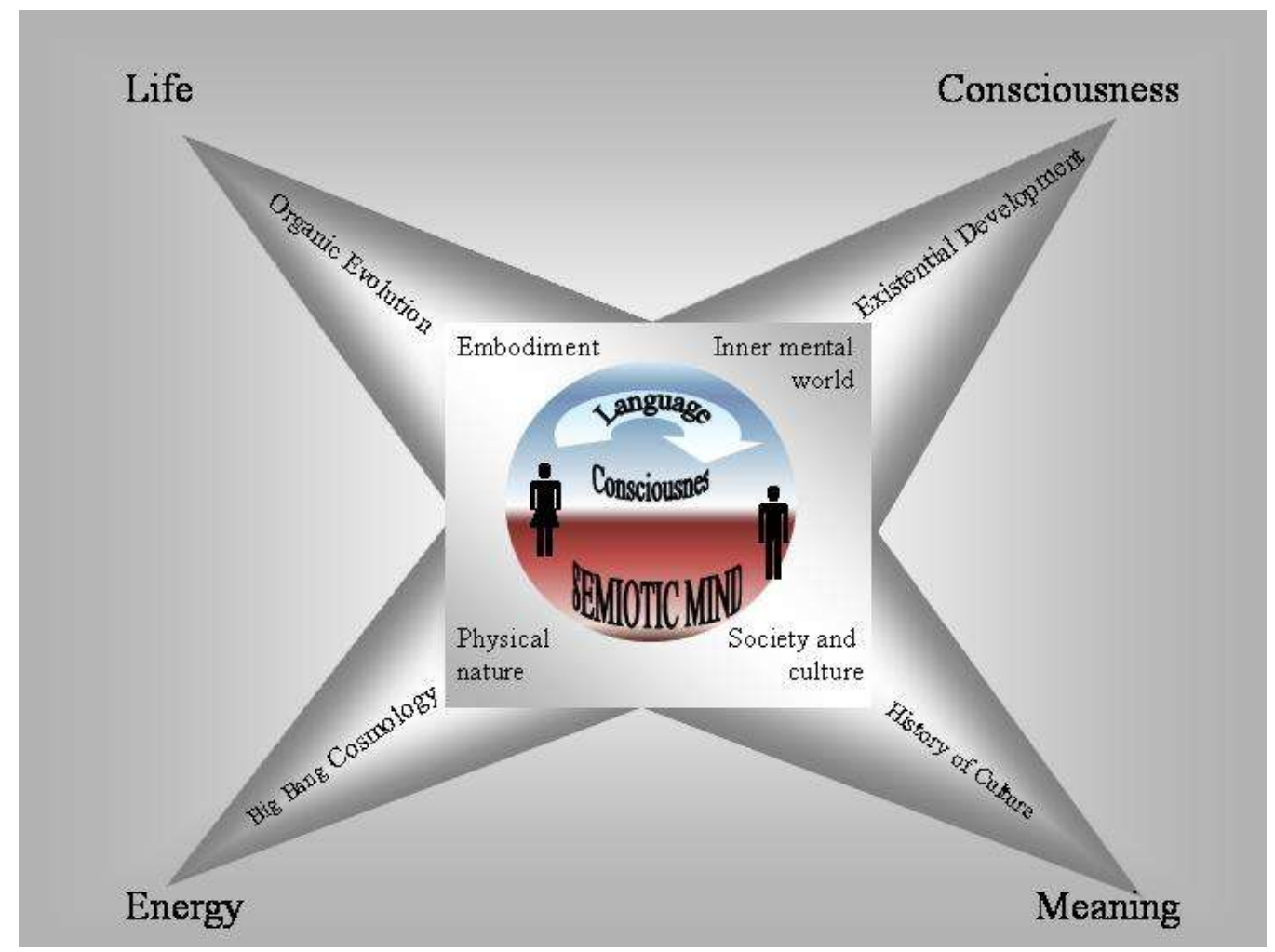

Figure 1: Visualizing how from the communicative social system of embodied minds' four main areas of knowledge arise: Usually physical nature is explained from energy and matter, living systems are explained from the development of life processes, social sign cultures are explained from the development of meaning and finally our inner mental world is explained from the development of consciousness.

I think that each of the four worlds calls on its own type of narrative. Physicists and chemists tend to see the universe as basically consisting of matter, energy and meaningless information. Biologists tend to end up seeing the universe basically as a living being, the social and cultural sciences tend to see the world as constructed from our social linguistic interpretations (unless they are dualistic and accept that nature is as science describes it and only culture is constructed by man). Those dealing with the phenomenological as pect of our being tend to be rather anti-scientific and anti-realistic often viewing the world as a product of consciousness as product of a linguistic system. But, like Peirce, I see the semiotic mind at the heart of all four worlds.

One of the strengths in Peirce's semiotic philosophy is that qualia and mind - as semiosis - are installed in the whole metaphysics from the beginning. They cannot be explained as such because they can only be inferred as a necessary prerequisite for producing the knowledge we want to discuss!

My main problem with the standard materialistic scientific evolutionary paradigm is that I cannot see how physics - as an external science - on the basis of the present definitions of matter, energy and determinist ic law can ever alone furnish us with the final understanding of our inner lives and how consciousness arises. If you work from an evolutionary view, combining the Big Bang theory with self-organizing thermo dynamics and chemistry adding Darwinism for biology systems, and proceed with a somewhat materialistic theory of the development of man and the history of language and culture, there is a severe problem of explaining life and consciousness as this inner quality of perception, feeling, volition and cognition that we all experience. I do not see quantum physics, the relativity theory or non-equilibrium thermodynamics as being of any particular help concerning this problem although they may be helpful to explain the physical aspect of consciousness. 
http://tripleC.uti.at

I am, therefore, hesitant to put the understanding of Peirce's semiotic philosophy into a scheme, explaining life and consciousness from the development of inanimate nature. The standard view of today combines an evolutionary view with a materialist ontology based on energy as the ultimate concept (in quantum physics, general relativity theory and thermodynamics), hoping to explain life as a phenomenon of chemical organization. When realizing that this is not enough, often the aid by some kind of objectivistic information concept is sought, although this adds fundamental new concepts, entities and ideas of organiza tion to the paradigm that is foreign to its basic metaphysical conceptions. The idea of my figure, and the epistemological turn it is illustrating, is to escape the great explanatory burden of reductionistic mainstream science, wanting to explain both life and consciousness from the basic assumption of energy and mechanistic mathematical laws. The cybersemiotic view sees scientific explanations as going from our present state, of socio-linguistically based conscious semiosis in self-organized autopoietic systems, towards a bet ter understanding of the prerequisites of language and the self-conscious being. The reduction made in any of the four directions has to remain consistent with the point of departure in the middle.

Science only to a limited degree explains the world or our place in it beyond our existential questions such as what is life, reality and meaning - not to talk of good and bad. We had knowledge before we had science. Knowledge - which can be defined as the combination of qualia, objects and interpretants in se miosis - is one of the big mysteries of the world. Being in the world in language, in body hood, in a meaningful social context we always have to start "in medias res". We will always be bound to make some meta physical presumptions based on our present understanding and they will always show later to be too limited. But Peirce's semiotics is a very good non-reductionistic framework to start from since its point of de parture is the semiotic mind, (see the centre of figure 1).

Somehow we will have to enlarge the conceptual framework within which we do science if we want to make a connection, also to the phenomenological aspect of reality and deal with the experience of meaning. Our task is to explain and understand all four aspects of reality and our explanations of any of the corners will only be one aspect of the explanation. My suggestion is that we start in the middle and extra polate toward the four corners. Trying to explain all from one corner is reductionism, no matter then in which corner we will end. For instance, I see social constructivism as the same reductionistic totalitarism as physicalism and the pan-informational paradigms.

Peirce's insistence on Secondness as an independent existence revealing itself in the end as the dynamic object for the final interpretant is an insurance against all sorts of (overly radical constructivism) too radical kinds of constructivism that loose their grip in reality and transform into either subjective or collect ive idealism.

One way to deal with this paradoxical problem would be to be less ambitious about the explanatory demands on science for the big scheme of things as Peirce shows in his deep integration of science, religion and philosophy with semiosis (Brier 2004). Science gives a good economic understanding of certain processes often in a way that allows prediction with a wanted precision within certain circumstances. But it does not give universal explanations of the construction of reality, energy, information, life, meaning, mind and consciousness.

Semiotics starts with the process of knowledge; how signification is taking place in living systems making perception and cognition possible. Peirce's semiotics unites our explanatory schemes of deduction and induction through abduction within the process of semiosis. Peirce suggests that we look at triadic semiosis as the fundamental process of reality. Consciousness is built from semiotic processes. In biosemiotics, semiosis is an essential part of all living systems. But again the problem of total explanation arises: can we go on from here to a pan-semiotic view without wanting to explain too much? My answer is that I doubt it. Instead I have argued that it seems fruitful to accept and work with five different levels of interaction in nature, but not necessarily assume any evolutionary causal links between them, i.e. indications that one level is supposed to give rise to the other assuming a one way up-causality:

1. A non-manifest level with hypercomplex interactions. The concept of vacuum in Quantum field theory is one attempt from science to describe this state but without a synechistic frame. 
2. An energy level with energy based causal interaction by natural forces.

3. An informational level with signal and/or code causality.

4. A semiotic level with sign game causality within and among living systems.

5. A linguistic level with language-game-causality based on meaning between conscious social systems.

\section{Critique of Current Approaches}

The point then is that the description of these levels did exist in different areas of modern science, but they have never been connected in one theoretical or even paradigmatic framework, although this is what mainstream eliminative mechanistic science tries to accomplish but on an insufficient philosophical background. Or to be more precise, the present and past attempts have all had different problems and inconsistencies:

1. Although classical mechanistic physics could describe certain connections, forces and regularities in nature mathematically, and later with the help of quantum mechanics the stability of matter, it is very difficult to think of actual evolution in a mechanistic worldview with rigid deterministic universal laws and a Newtonian reversible time (Prigogine/Stengers 1984).

2. This is solved in the thermodynamic atomistic view based on complexity, self-organizing dissipative structures and irreversible time. But here it is still difficult to understand how information and cognition can arise and self-organize from pure physical matter and energy.

3. In the pan-informational paradigm information as organizing power is present from the start. This makes self-organization and the emergence of cognition more understandable especially when it is es tablished in general systems theory that has an organismic and emergent evolutionary worldview. But in this view it is still difficult to understand how living systems can arise as individual beings, how they treat information differently from mechanical cybernetic systems, and also what is the special quality of the semiotic creativity of self-conscious linguistic embodied beings.

4. In second order cybernetics and autopoiesis theory, the idea of closure on the biological, psychological and social communicative level explained by the concept of autopoiesis: living systems' self-organizing, self-maintaining and self-producing ability, much clarifies the special self-preserving ability and cognition as well as the creation of an individualistic point of view. The conception - especially of Maturana and Varela and also von Foerster - also comes close to Jacob von Uexküll's Umweltslehre (Brier 2001a). They all represent some kind of bio-constructivism. Unfortunately it tends to be rather idealistic, sometimes even solipsistic in certain formulations while, at the same time, it "paradoxically" insists on the material reality of a biologic(al) observing system.

5. In Peircian semiotic philosophy these levels can be bound together by Synechism, Tychism and Agapism combined with the evolutionary view of the interaction of Firstness, Secondness and Thirdness. The view of Firstness as a blend of mind and matter qualities and as containing qualia and living feet ing with a tendency to take habits is crucial to understand the self-organizing capabilities of nature and how, what seem as "dead" matter, through self-organization in evolution can become autopoietic and alive and has cognitive/semiotic abilities and feelings (Brier 1999a). Re-interpreting Uexküll on this foundation creates a biosemiotics that is much more suited to encompass the phenomenological as pect of life and cognition, which is now conceptualised as signification (Brier 2001a). Still, aspects of the development of embodiment, which Uexküll did not think of, are partly missing. Concepts of clos ure and self-organization of biological, psychological and social systems and their differentiation, de veloped in second order cybernetics and autopoiesis theory, need to be integrated (Brier 2000a). Both Hoffmeyer and Emmeche do work with these aspects in the theory development, which is already transgressing the original limits of biosemiotics. 
http://tripleC.uti.at

These are some of my reasons for being sceptical about totalitarian and reductionistic explanatory paradigms like mechanicism, pan-informationalism and a pan-semiotic without thresholds, but also too radical forms of constructivism that are out of touch with any non-linguistic reality. This is why the discus sion of the semiotic threshold in a Peircian framework becomes so crucial.

The cybernetic thinking of self-organization and system closure has, in my opinion, made an important contribution to our understanding of living systems. Already Jacob von Uexküll used some basic cybernet ics in his "Funktionskreis". We can see the foundation laid both for biosemiotics and biocybernetics (second order cybernetics and autopoiesis theory) in Uexküll's work. But a combination of Peircian semiotics and modern cybernetics is necessary to make the theory broad enough in order to cover what is now called biosemiotics and to make the framework develop beyond the present stage, encompassing the understanding of the problem of the semiotic threshold, which is a core-epistemological problem. Biosemiotics, in name and scope, is partly neglecting or ignoring the contribution of second order cybernetics and autopoietic theory. However, the cyberneticians, even as their work is combined and further developed into the area of human social communication as in Luhmann's work, instead tend to ignore the semiotic component too much (Ort/Marcus 1999). In my view, to be able to combine the fruitful work of both camps a broader foundation is needed. This is why I call my work Cybersemiotics.

The cybersemiotic approach that I am working on, attempts to unite cybernetic, systemic informational and semiotic approaches to deal with the problems of self-organization, intentionality, selection of differences and constructivism avoiding solipsism and idealism. This is - among other things - done by giving decisive attention to the role of body hood in the construction of meaning using the viable parts of the above-described five views by combining informational, cybernetic and Peircian biosemiotic approaches in non-totalitarian or non-pan versions.

The cybersemiotic approach thus ascribes to a Peircian and Uexküllian biosemiotics and combines it with the theories of second order cybernetics (von Foerster) and autopoiesis (Maturana and Varela 1980 and Luhmann 1995) that are already visible in Uexküll's "Funktionskreis" (Sebeok 1986). It uses a Peircian and ethological extension of Wittgenstein's pragmatic language theory to distinguish between the sign games of biological systems and the language games of humans. It acknowledges the independent being of Firstness and Secondness (what would normally be called the "physical world" but is now based in Peifcian metaphysics). Finally it underlines that the cybernetic machines, such as computers and robots are not truly semiotic, but quasi or proto-semiotic (Nöth 2002). Machines lack autopoiesis, reproduction, codeduality and inner organization of membranes (Hoffmeyer 1998) and thus an individually and species based motivation and intentionality (Brier 1995 and 1998a). Combining the results of modern science with Peif cian biosemiotics the cybersemiotic framework operates with five levels of existence:

1. A primary chaotic level of continuity, quality and potentiality with a tendency to take habits (Firstness). This goes beyond the physical conception of vacuum fields that are still pure materialistic, but may be included as an aspect.

2. A "causal" level of matter, energy and causality by natural forces. This is Secondness that has, as its inner aspect, will and mental force.

3. An informational cybernetic system level of informational signals, which encompasses the goal-ori ented mechanical systems described by first order classical cybernetics. Described from a cybersemi otic view, concepts of information as signals of differences only make sense as quasi signs (see Nöth 2002 for an analysis).

4. The semiotic level belonging to all living systems (biosemiotics), which are so far the only systems capable of true triadic semiosis (producing signification spheres in sign games). This level encompasses the work of Uexküll (1934) and the ethologists such as Lorenz (1970-71 and 1973) and Tinbergen (1973) in a broader semiotic framework (Brier 1999b).

5. The level of conscious languaging systems (language games, arguments), to our knowledge so far only occupied by humans. 
Sign-making is thus immanent in nature, but only manifest in full triadic semiosis in living systems. Cybersemiotics has, so far, sided with biosemiotics in not accepting physio-semiotics as a full-fledged semi osis.

\section{The Cybersemiotic Epistemology}

Ever since Umberto Eco formulated the problem of the "semiotic threshold" in 1976, semiotics, especially Peircian semiotics, has developed even further into the realm of biology. The efforts of Thomas Sebeok $(1976,1989)$, in particular, has lead to the development of a biosemiotics encompassing all living systems as sign users - including plants and microorganisms. This semiotics has even moved into the ofganisms describing semiosis between body cells and in the cells (endosemiotics) (Uexküll et al. 1993).

The question that is now becoming essential for the whole debate about the possibility of a transdisciplinary information/signification science is, if the biosemiotic Peircian framework that includes and reformu lates Jacob von Uexküll's theoretical biology will comprise un-interpreted "natural" objects as signs. Most obvious phenomena are autocatalytic and dissipative structures that emerge by the spontaneous genera tion of order and patterns in nature. These objects were originally described in physio-chemical terms. Now some of the pan-informational paradigm adherents, such as Stonier, want to explain them in purely informational terms.

From a Peircian view these phenomena are protosemiotic, or quasisemiotic when compared to the semiosis of living systems, as they are only displays of Secondness (Nöth 2001). To distinguish the semiosis of the living systems from physiosemiosis, I have applied the term sign games or biosemiosis (Brier 1995). We are not talking about the situation that any natural thing can become a sign when placed in a meaningful context by a living system, but about the objects and their processes per se. The present quote from Peirce gives a very clear idea of the distinction between what the thermometer as a physical thing does per se, and how it works when interpreted by a doctor:

"The acceleration of the pulse is probably a symptom of fever, and the rise of the mercury in an ordinary thermometer ... is an index of an increase of atmospheric temperature, which, nevertheless, acts upon it in a purely brute and dyadic way. In these cases, however, a mental representation of the index is produced, which mental representation is called the immediate object of the sign; and this object does triadically produce the intended, or proper, effect of the sign strictly by means of another mental sign" (CP 5.473 from Nöth 2002).

Another similar problem is the question of what machines, like computers, are processing when no hur mans are interpreting. Is it signs or just signals? We know that we codify the signals so they carry meaning for us in our context and therefore they are signs to us, and forwarding that sign's meaning through a pragmatic view is what they do. But doesn't this have to be in a living context where meaning is already intro duced through embodied minds existence? Relating to the question of the semioticity of calculating machines, Nöth explains how Peirce coined the term "quasi-semiosis" to deal with this problem. He writes:

"The term quasi-sign suggests an answer to the question whether there can be semiosis in a machine of the kind which Peirce knew. A quasi-sign is only in certain respects like a sign, but it does not fulfil all criteria of semiosis. While some criteria of semiosis may be present in machines, others are missing. The concept of quasi-sign thus suggests degrees of semioticity. Quasi-semiosis does not only begin with calcur lating machines. It can be found in processes in which much simpler instruments are involved" (Nöth 2002: 8).

Through his synechism Peirce did not believe in a separation of mind and matter in a strict dualism. Peirce's concept of mind is then extremely broad and does not need to include consciousness or intentionality but only goal directedness. The use of the term quasi-semiosis to designate "degenerated" semiosis near the shift between Secondness, in machines, and Thirdness of the biosemiotic sign games, stems first of all from a lack of a triadic object relation. Nöth writes:

"Evidence of the quasi-semiotic nature of data processing comes from the dyadic nature of the signs involved. The view that sign processing in computers is based on dyadic relationships is implicit in a widely 
held theory which states that computers can only process signals..., i.e., mechanical stimuli followed by automatic reactions. Winograd \& Flores (1987), e.g., refer to signal processing when they write: "One could describe the operations of a digital computer merely as a sequence of electrical impulses traveling through a complex net of electronic elements, without considering these impulses as symbols for anything" .... What is missing for these signs to develop from dyadic to triadic signs is an object relationship. The dyadic relations are merely dyadic relations of signification, but there is no denotation, no "window to the world" which allows to relate the sign to an object of experience... the messages produced by a computer in the interface of humans and machines are either messages conveyed by a human sender and mediated by the computer or they are quasi-signs resulting from an automatic and deterministic extension of human semiosis" (Nöth 2002: 8).

This brings us right into cybernetics, especially Bateson's. Here information is a difference that makes a difference for a cybernetically defined "mind". This mind works primarily on differences with feedback loops based on energy. The energy is not important for the coding process per se. But the critique directed at cybernetics' concept of information and meaning has exactly been underlining that this type of system based on information theory is only functionalistic and does not have the capacity of encompassing meaning in a biological, not to say a human perspective (Brier 1992). The problems between these two transdisciplinary paradigms of information and signification seem to stem from the fact that they are coming from opposite directions of the hierarchy of science and humanities when they develop their theories of messages.

It seems to me then that if we want to get beyond just accepting that we have two incompatible paradigms, we must abandon the pan-views. In the spirit of Niels Bohr's complementarity theory we must take one step back and:

1. Give up some of our ambitions of getting "to the bottom of things" including laws and causality with our scientific approaches.

2. We must attempt to broaden our conceptual framework by - amongst other things - integrating the observer and doer in our framework.

Peirce clearly does this in his triadic model of semiosis where the interpretant is part of the theory through his concepts of the immediate and dynamic object. A similar development has been carried through in second order cybernetics and autopoiesis theory.

Maturana and Varela in their theory of autopoiesis do not apply the word information at all when cogni tion is to be understood from within the autopoietic system. Nothing is transferred from the environment to the living system that can be designated meaningful information. But they admit that you can say that, when you observe from the outside, it looks like the system has obtained information. A way to describe it is to say that information is created inside the autopoietic system when it receives a disturbance, which as a species it is prepared for by the creation of a structural coupling. Maturana and Varela (1980) do not view the structural coupling as an information channel because no representations are moved through it. Ethologists would say it had an instinctual perception where sign stimuli elicited an Innate Release Response Mechanism (IRM) that released a preprogrammed instinctive behaviour (see for instance Brier 2000b, 2001) Anyway, this constructivistic biological cybernetics stresses the intimate evolutionary and developmental dynamical relation between environment and organism. One can then from a cybersemiotic perspective view autopoiesis combined with Hoffmeyer's (1998) further points as a condition for differences in the environment becoming meaningful signs through the process of semiosis. But Maturana and Varela's concepts do not in themselves fit with neither concepts of information science, nor with semiotic concepts, such as semiosis as an interpretation.

It is now well established that there is an area of nature between the physical causal level and the level of biosemiosis. I have argued that this level is the area that cybernetics and information science has con ceptualised. In my previous works I have argued that cybernetic information science also erases a threshold between causality and information when all nature becomes informationalised. It also ignores the level of meaning, or what we now call second order semiosis, suggested to be the subject area of biosemi 
osis. When information theory attempts to encompass the area of meaning and semantics it passes and destroys the semiotic threshold too, but now in the other direction, blurring the difference between informa tional and semiotic processes, and thereby between mechanical signal manipulation or quasi-semiotic systems and living systems. This produces all sorts of simplistic theories about intelligences that are not able to grasp the cognitive processes special for embodied living systems, not to speak of conscious socio-linguistic systems.

Even though I do not think that any of our systematic conceptual knowledge systems can fully grasp the reality. I agree with Peirce and Bohm (1983) that there must be some kind of infolded dynamic order in our reality, even though it is just potential qualia and tendency to take habits. If this were not so, then the Thirdness, which makes it possible for us to know something through the establishment of interpretants based on the perception of some kind of regularity of differences would not be possible.

My point here is to say that sign making is the threshold between cybernetics and semiotics. That to make a difference make a difference is to establish a sign for it (the interpretant) in an embodied mind. Before that it is only second order cybernetic signals or quasi-semiotic according to Peirce. The whole subject area of cybernetic information theory is in my view then quasi-semiotic. Underneath that is the physicochemical level that in general is best described in terms of energy, matter and causality by natural forces (Secondness), but it does have Thirdness processes over long time frames. If you want, this is a kind of semiosis over long time with the universe as subject. ${ }^{3}$ You can then call the biosemiotic level semiosis with the species as subject and, finally, human language games as semiosis with individual cultural persons (persona) as subject.

Cybersemiotics is a development of biosemiotics using, among other things, Niklas Luhmann's work for further development. Below we will go into more detail describing a model for the levels of signification and communication in humans.

\section{Luhmann's Triadic Autopoietic Systems}

Luhmann has generalized the autopoietic concept of Maturana and Varela (1980) in order to also comprise psychological thinking systems and socio-communicative systems. He views the psyche as a silent inner system, a closed system of perception, emotions and volitions. A special linguistic system has to be created for communication to happen. Communication is again an organizationally closed system. Only communication communicates. Social systems are communicative systems with human bodies and minds as surroundings! See figure 2 .

\footnotetext{
3 The formulation is a result of a discussion with Jesper Hoffmeyer on April 3, 2001, in my office at KVL. As such it is a way to inter prete Deely's physiosemiosis theory.
} 


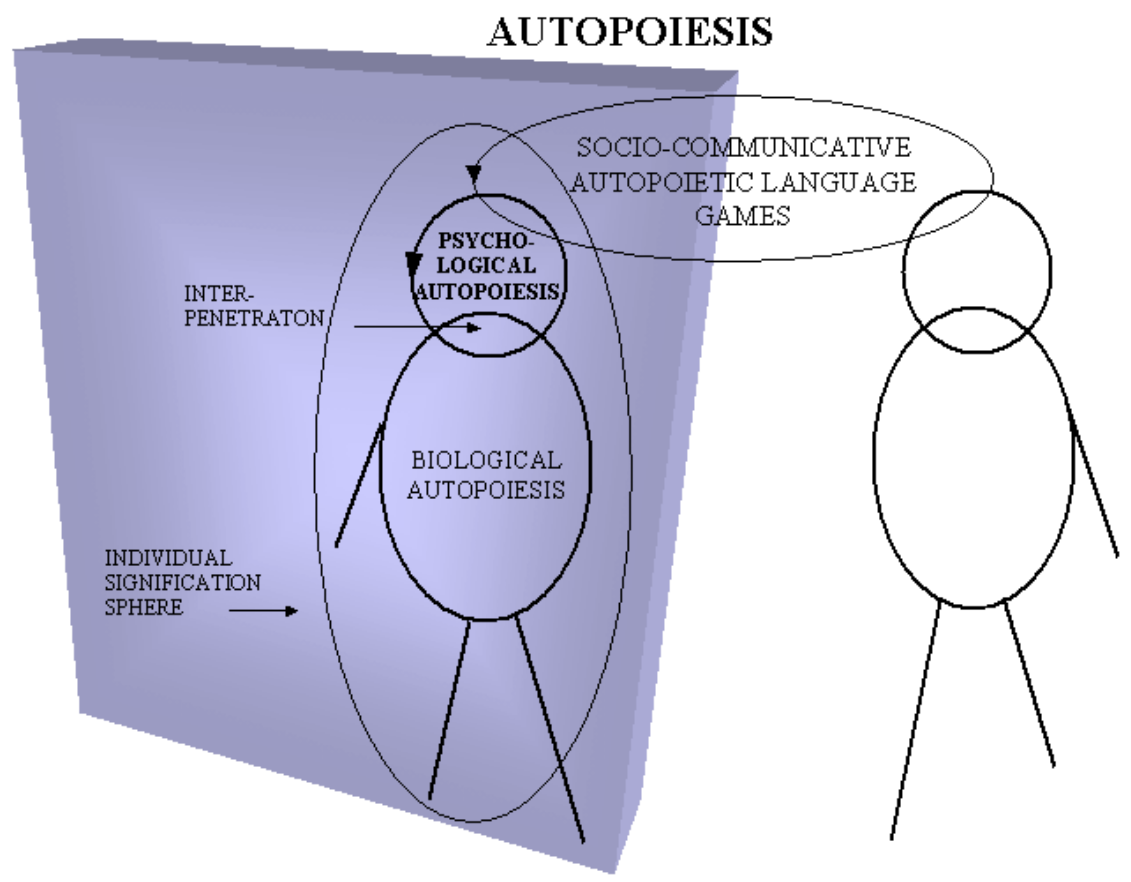

Figure 2: Three organizationally closed systems working separately make communication possible. This figure is the first in a series of visual summaries of my theory. They are not the theory themselves, but very simplified symbolic icons that hopefully can give some kind of visual overview easy to remember. But one must not forget that they are only symbolic iconic pictures and not a map of where the various systems are placed in the body. Psychological processes for example are not only in the head and so on. The signification sphere is the biosemiotic term for Uexküll's Umwelt and Maturana's "Cognitive domain".

To Luhmann (1995) communication is a sequence of selections, namely of 1) information, 2) utterance and 3) meaning. The two first have to be made by what we traditionally call "the sender", the last one by the receiver. He chooses his understanding of the signs produced, and then one could say that a message is produced when the receiver says something that the sender chooses to understand as a confirmation of understanding of his first message. Finally, in a fourth selection the message is connected to present practice.

Although his view of information is loosely based on Shannon's concept, it differs from it in that Luhmann (1995) does not believe in its use outside of human social communication. Thus, he does not want to generalize it outside the analysis of human messages. Also Luhmann does not seem to believe that information exists in nature independently of human perception. The information concept functions as a quantitative aspect within a meaningful human context. Further he combines information with the aspects of utterance and meaning. Luhmann stresses that both the sender and the receiver have to make their choices to produce a meaningful message. I think that instinctive reactions would also count as such a choice. Information is choices related to subject matter, utterance is choices pertaining to the way to say something, and meaning is the choices of interpretation of the listener depending on his evaluation of the human context. I think that Luhmann's theory has problems producing a concept of meaning that relates deeply to the flesh, blood and life (conditions) of biological systems and the existential conditions of human consciousness. Here pragmatic language philosophy, like Wittgenstein's language game theory and Lakoff and Johnson's embodied cognitive semantics combined with ethology, all seen within Peircian biosemiotic framework (Brier 2000a), tell us that signs as concepts and classifications arise in our embodied biological and social "life forms". From our inner world we express our bodily experiences in social relations. It is es pecially regarding the social communicative construction of meaning that Luhmann's theory connects so well with semiotics. But Luhmann himself did not connect to semiotics in any systematic way. In the following I will reformulate this problem area from a cybersemiotic viewpoint. 


\section{The Cybersemiotic View of Cognition and Communication}

One way to understand our inner mental world is to see it as a way of representing our bodily interactions with the environment through the constructions of a felt signification sphere. In this way an individual "point of view" as a centre of cognition, interest and interpretation is created. What Spinoza calls conatus, self-value and self-interest in preserving the individual's and species' self-organizing structure is basic to living systems' ability to signify. But this individual signification sphere is again perturbed by the species' specific social interactions starting with mating, rearing of the young, competing for hunting territory, and hierarchy in the group, co-operation in food gathering and hunting. These social interactive activities first generate sign games, and later in evolution, the human language games.

The construction or development of meaningful and informative messages has as a prerequisite autopoiesis, signification and conatus/motivation/intentionality. It is only within this triad that the selections of information, utterance and meaning are possible.

Viewed in this way, Luhmann's three autopoietic systems (see Luhmann 1990) are all needed to create the meaning of a message and one needs the sign concept to understand their interaction. One way of getting out of the impasse of Luhmann's functionalism, where the role of body and mind in the production and meaning of social communication has not been adequately grasped by theory, is to view the interpenetration between the three organizationally closed systems semiotically. Signs acquire meaning where the systems interpenetrate. Interpenetration is Luhmann's term for the interaction between biological autopoiesis, psychic closure and the socio-communicative system with its own closure at the social level. My hypothesis is that sign and language games arise on the basis of the interpenetration of the three different autopoietic systems.

Meaning is seen as being generated by the interpenetration of the systems. For example, language is a part of the socio-communicative system, but it does not really acquire meaning before it interpenetrates with the psychic system and gets to indicate differences of emotions, volitions and perceptions "putting words" on our silent inner being. But our cognitive, emotional and volitional qualities would only have a weak connection to reality if they were not connected to the survival of the living systems' organization as a body in its interaction with the environment's differences in the development of a signification sphere in the evolution of the species.

Biosemiotics and metaphor theory have argued extensively for the importance of embodiment in semi osis. In Brier (2000a), I have tried to show the connection between the biosemiotic (ethologically based) concept of motivation and the motivational concept of embodied cognitive semantics. I have shown that ethology and embodied metaphor theory have both discovered that the conception of a sign as standing for something for somebody in a particular way is controlled by some releasing mechanisms that connect motivation, perception and behaviour/action into one systemic process as already Jacob von Uexküll de scribed in his "Funktionskreis" and, which Heinz von Foerster refers to as perceptual "eigenvalues". Instinctually, the actual IRM (Innate Release Mechanism) is chosen through the urge coming from a specific motivation. This is again based on biological expectancies and vital needs, like for food and mating. I argue that the linguistic motivation that Lakoff and Johnson claim controls the ICM (Idealized Conceptual Models) have connection to the biological motivations in many instances. This is obvious in the much-used example where a woman classifies a man as a bachelor, and therefore as a potential mating partner. It is our bio-psychological embodiment that ties these relations together.

Further I showed that a phenomenological-emotional concept was necessary to understand the production of meaning. I want to point out here that this is consistent with Peirce's placing of feeling as an attribute of Firstness. In his evolutionary theory, feeling becomes an immanent inner reality, also in matter.

Knowledge systems thus unfold from our bio-psycho-socio-linguistic conscious being. Their function is to help us orient (ourselves) in the world and help us act together in the most fruitful way, but they do not explain us to ourselves. Peirce's view that we cannot with any good reasons split the concepts of mind and matter from the beginning, is a very sound and profound foundation for a transdisciplinary metaphysical framework. I do not see any good reason why the inner world of cognition, emotions and volition should not 
be accepted as just as real as the physical world as well as our cultural world of signs and meaning. Finally to both the spiritualist and the materialist, embodied life, even with only one cell as the body, has to be a basic part of, or a component of constructing reality. We are thinking in or maybe even with the body. The psyche and its inner world arise within and between biological systems or bodies. With Peirce one may say that there will always be some kind of psyche in any kind of biological autopoietic and code dual system. Still, a partly autonomous inner world of emotions, perceptions and volitions, only seems to arise in multicellular chordates with a central nervous system. Lorenz (1973) argues that such a system with emotions and experiences of pleasure is necessary for animals to have appetitive behaviour, searching for the objects or situations that can elicit their instinctual behaviour and release the motivational urge built up behind it. This is qualitatively different from how reflexes function on a signal, which is a proto-semiotic informa tional level. Instinctual sign function is on a genuine semiotic level.

Luhmann's theory of the human socio-communicative being consisting of three levels of autopoiesis can be used in cybersemiotics to distinguish between 1) the languaging (Maturana) of the biological systems, which is the coordination of coordination of behaviours between individuals of a species on the reflexive signal level, 2) the motivation driven sign games of the bio-psychological systems and, finally, 3) the well driven language games level of the self-conscious linguistic human through generalized media in the socio-communicative systems. A semiotic understanding has thus been added to Luhmann's conception, and his theory has been placed in the Peircian triadic metaphysics. In the following section, I will explain and develop this further.

\section{Intrasemiotics}

It is obvious that what we call language games arises in social contexts where we use our mind to co ordinate our wilful actions and urges with fellow members of our culture. Some of these language games are then about our conceptions of nature, now filtered through our common culture and language. But underneath that, we also have emotional and instinctual bio-psychological sign games (Brier 1995) that these function for humans as unconscious paralinguistic signs, such as facial mimics, hand movement gestures and body positions with origin in the evolution of species-specific signification processes in living systems.

Simultaneously, we also have an internal communication going on between our mind and body. In Luhmann'$s$ version it is something different from what Kull (1998) calls psychosomatics, as it is not a direct interaction with culture but only with the psyche. On the other hand it is not only endosemiosis. The terms endosemiosis and exosemiosis were probably both coined by Sebeok (1976: 3), endosemiosis denoting the semiosis that takes place inside the organisms, and exosemiosis being the sign process that occurs between organisms. Endosemiosis became a common term in semiotic discourse (see Uexküll et. al. 1993), meaning a semiotic interaction at a purely biological level between cells, tissues and organs. Nöth and Kull (2001) introduced the term ecosemiotics, specifically for the signification process of non-intentional signs from the environment or other living beings that take a meaning for another organism, for instance, to a hunting animal, the scent of prey. Thus the sign signifying an organism, as a suitable prey is not intentionally emitted by the organism preyed on, and is therefore rather ecosemiotic than exosemiotic. What can we then call the internal semiotic interaction between the biological and the psychological systems?

I term the interaction between the psyche and the linguistic system thought semiotics. This is where our culture through concepts offers us possible classifications of our inner state of feelings, perceptions and volitions. These, in their non-conceptual or pre-linguistic states not recognized by conceptual consciousness, I call phenosemiotic processes. For short I just call them phenosemiosis. See figure 3. 


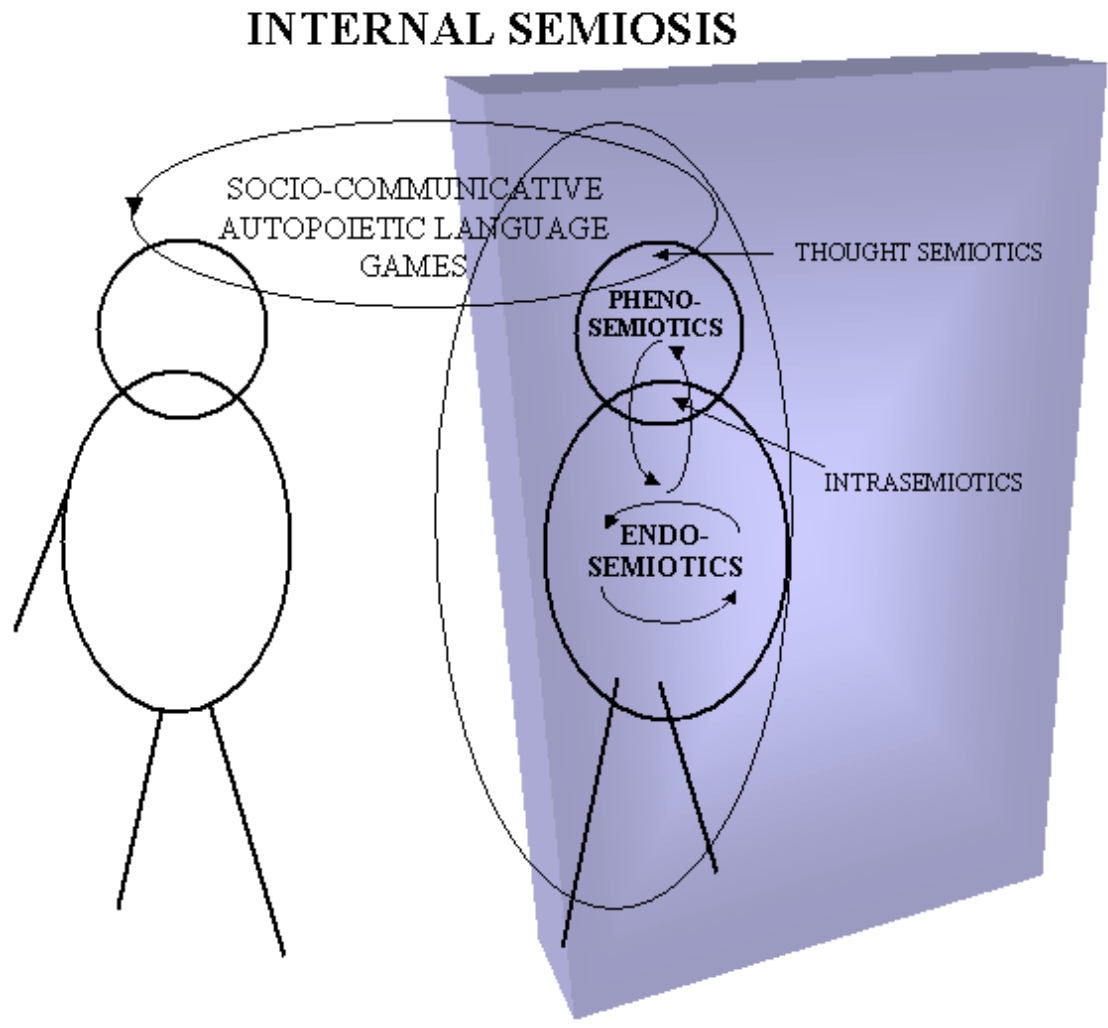

Figure 3: shows in a symbolic iconic simplified way the relation between phenosemiotics (Prelinguistic experiences), endosemiotics, thought semiotics and intrasemiotics (semiotic interaction between the biological and the psychological levels, but now reformulated in cybersemiotic terms). But remember that phenosemiotics is not only in the head and so on.

As the interactions between the psyche and the body are internal bodily, but not pure biological as in endosemiotics, I call the semiotic aspect of this interpenetration between the biological and the psychological autopoiesis intrasemiotics (Brier 2000b). See figure 3. These different terms are coined to remind us that we deal with different kinds of semiotics. In the future, we will have to study more specifically the way semiosis is created in each instance.

Today we know that there are semiotic interactions between the hormone systems, the transmitters in the brain and the immune system and that their interactions are very important for the establishment of the autopoietic system of second order, which a multicellular organism constructs as a kind of biological self. Its parts are cells that are themselves autopoietic systems and these are again on a new level organized to an autopoietic system. But we do not know very well what the relations are between our lived inner world of feeling, volitions and intensions and this system. It seems that certain kinds of attention on bodily functions, such as imaging, can create physiological effects in this combined system. As mentioned above, this is partly carried by different substances that have a sign effect on organs and specific cell types in the body (endosemiotics). We also know that our hormonal level influences our sexual and maternal responses. Fear turns on a series of chemicals that change the state and reaction time of several body functions, and so on. This is a very significant part of the embodiment of our mind, but intrasemiotics seem to function as meta-patterns of endosemiotic processes. For example, our state of mind determines our body posture through the tightness of our muscles. There is a subtle interplay between our perceptions, thoughts and feelings and bodily state working among other things through the reticular activation system. There is still a lot we do not know about the interaction between these systems.

The nervous system, the hormonal system and the immune system seem to be incorporated into one big self-organized sign web. Now, the autopoietic description of living cybernetic systems with closure does not really open for sign production per se, and semiotics in itself does not reflect very much about the role of embodiment in creating signification. Thus, the cybersemiotic suggestion to solve this problem is that signs are produced when the systems interpenetrate in different ways. The three closed systems produce 
different kinds of semiosis and signification through different types of interpenetration, plus a level of structural couplings and cybernetic "languaging", as Maturana and Varela (1980) call it. See figure 4.

\section{EXOSEMIOTICS}

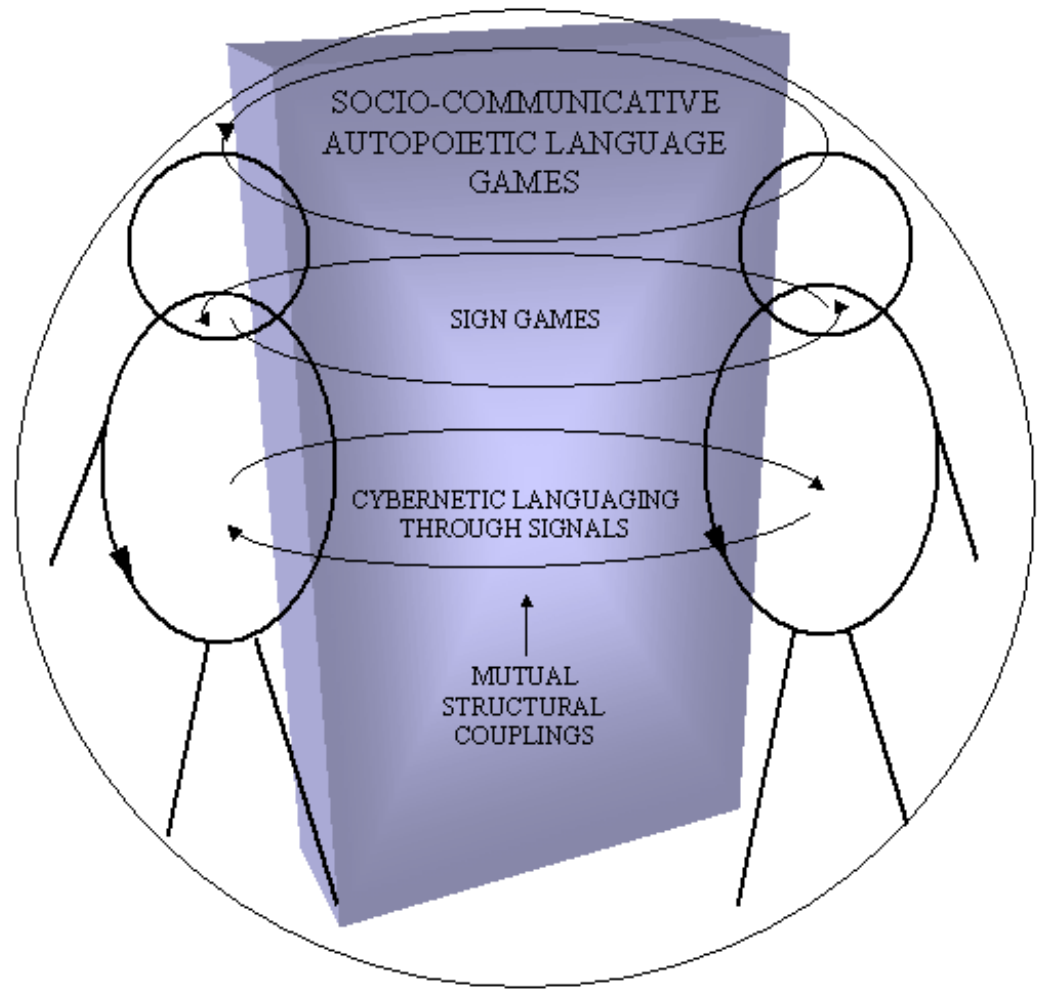

Figure 4: shows the three different levels of communication systems described in cybersemiotics. At the foundation is the informational exchange of signals of orientation and other reflexes. On the next level we find the biosemiotic sign games of all living systems mostly within the species, which still works for the basic biological drives in humans. Then there is the level of language interchange in dialogue between self-conscious persons. Caution of the simplification also goes for this figure.

Autopoiesis theory underlines that two interpenetrating systems primarily are closed black boxes to each other. But interpenetration between them develops a coordination of coordination of behaviour that he calls languaging. Parts of these systems are inherited on reflexive and instinctual levels and are foundational for communication to develop. Then, in my opinion, it is through the reciprocal structural coupling formed between the two systems signs can be produced and exchanged. Maturana's concept of languaging (coordination of co-ordinations of behaviour) seems to be the bio-psychological connection between two individuals in a social species. But it is not the sign and/or language game as such; it is the underlying cognit ive coupling that is the coordination necessary for communication to develop as a signification system with its own organizational closure. I would, therefore, suggest that we distinguish between languaging and sign games at the level between reflexes and instinctual movements (Brier 2000b) as already mentioned (see figure 3). Thus, the schooling behaviour of fish is reflexive informational but courtship communication is instinctual sign games. The perception eliciting reflexes is independent of motivation, whereas the perception of sign stimuli is motivation-dependent, which leads into the instinctual sign games. Ethologists would here point to how certain instinctual movements become ritualised and get a release value for instinctive behaviour as "sign-stimuli". As Lorenz (1973), in his last period, realized that emotions had to be connected to the performances of instinctual movements to create the motivational urge of appetitive behaviour, we here have criteria to distinguish between the two levels (Brier 2000b). We here see how the connection between signs and internal or phenomenological understanding is constructed. Lakoff (1987), and Lakoff and Johnson (1998) have shown us how this basic mechanism of bodily meaning can be explained, by metaphorical processes, to encompass socially and culturally produced signs. 
Based on ethology and biosemiotics I claim that our cognition manifests itself as embodied semiosis, motivated in our biological social interest that is a powerful creator of structure and meaning in our signification sphere. Most animal behaviour is - like much of our linguistic categorizations and use of metaphors considered to be unconscious. Still ethologists had to realize that motivation is not a physiological concept (Brier 1992, 1998), emotional experiences are connected to the perception and behaviours with an instinctive basis.

Sign games are developed into language games through evolution and in the life of the infant human. As we are born and grow into human social communication the psyche is perfused with signs. Our mind is infected with language and we become semiotic cyborgs or what we call humans. We are in this view born as animals with a capacity to construct this interpenetration between the psychic and socio-communicative systems, creating internal interpretants that are meaningful to us because of the mutual structural couplings of languaging established in evolution.

Meaning is seen in biosemiotics, cognitive semantics, autopoiesis theory and ethology as embodied. But with the new cybernetics and von Uexküll, I suggest that embodiment is thought of as much broader than only the structure of the nervous system, or even the integration of the neurotransmitter, the hormone and the immune systems through reaction to common sign substances that they secrete. As Fogh Kirkeby (1997) suggests, we should look at the body-mind or the body-thought as a complex phenomenological dynamical system, including the construction of the environment and the other (body-mind) systems that make it possible for signification to appear.

Realizing that a signification sphere not only pertains to the environment, but also to the perception of other members of the species in cultural and proto-cultural behaviour as well as to perceptions of own mind and body hood, I use a little "eco" as a prefix to the signification sphere, when it is the aspect of it pertaining especially to non-intentional nature and culture outside the species in question. In both inanimate nature, as well as in other species and in cultural processes, we can observe differences that signify meaning to us, although never intended by the object. See figure 5 where I sum up the concepts developed so far.

\section{The Cybersemiotic Model of Biosemiotics}

I am going to present a rather complicated model, differentiating between different levels of semiosis and signalling, pertaining to some of the questions already brought up about the basis and the thresholds of semiosis within biosemiosis, but without going to a pan-semiotic view.

See figure 5 for an overview of the cybersemiotic concepts built up so far. On the left side we see only the cybernetic-autopoietic-functionalistic described processes. In the middle we see the communicative as pects or the exosemiotics between two organisms. On the right we then look at the internal-semiotics of the organism. Finally, to the far right we look at the organism's perceptual connections to the environment, creating its signification sphere. With Nöth and Kull (2001) we call this signification aspect eco-semiotics.

Ecosemiotics focuses on the part of our language that is about how all living systems represent nature in signification spheres, ending with language games in culture. Cybersemiotics points out that the basis of these eco-language games is the eco-sign games of animals, combined with a signification sphere, and created through evolution. Further, these are based on an intricate interplay between the living system and its environment, establishing what Maturana and Varela call structural couplings. The signification sphere is a workable model of nature for this living system that as a species has existed and evolved over millions of years. 


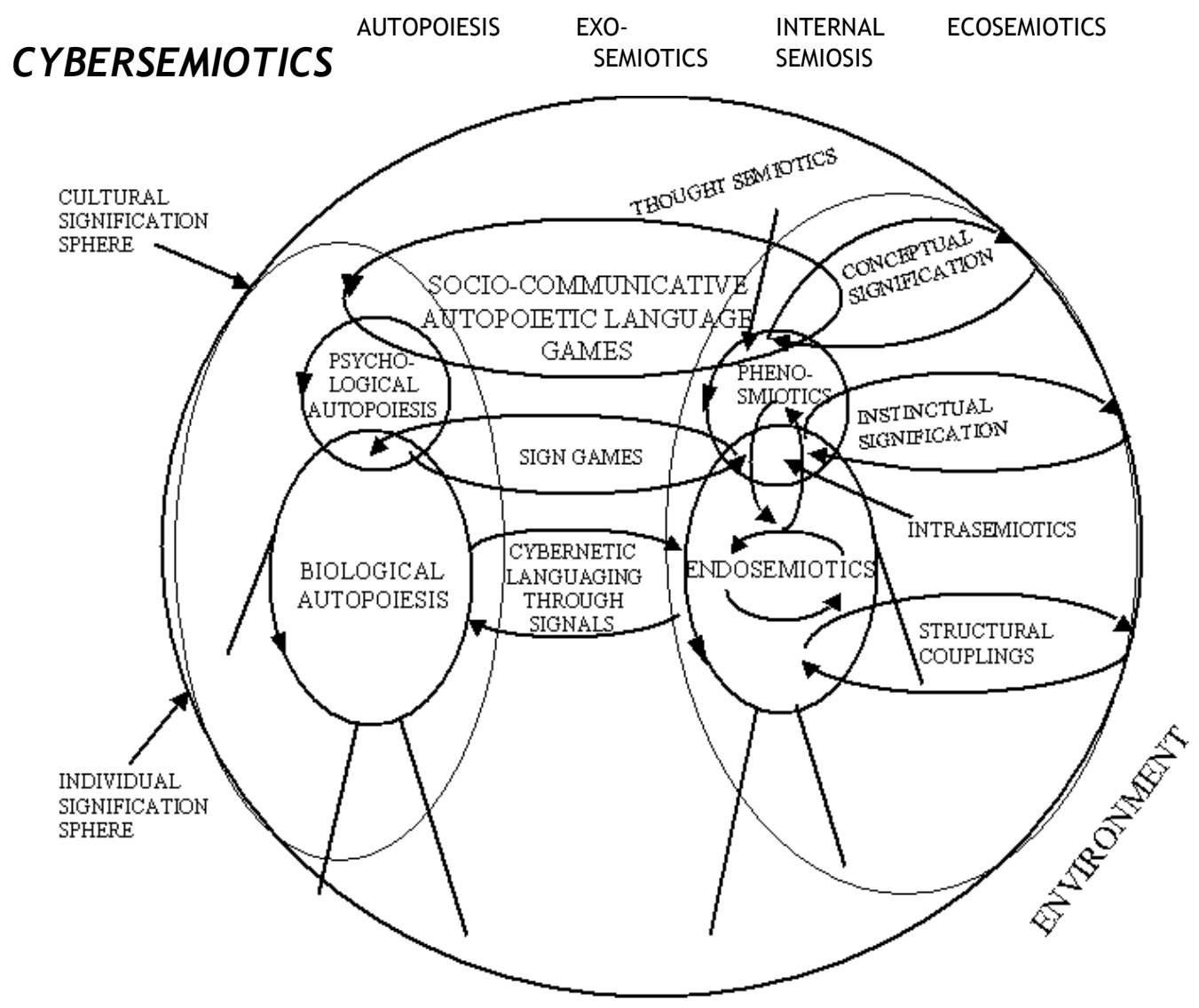

Figure 5: Cybersemiotic model classifying different types of semiosis and proto-semiotic processes: The model is a cybersemiotic development of the Luhmann model shown in figure one. The localization of the processes have nothing to do with the actual bodily locations (as the head, for instance, is also a part of the biological autopoiesis), and have endosemiotic processes. To limit the complexity, I have placed all the cybernetic-autopoietic concepts on the left person and all the semiotic ones at the person to the right. But all concepts concern both persons. Each person is placed in a signification sphere. When these are combined through socio-communicative autopoietic language games a common signification sphere of culture is created. One part of ecosemiotics signification is based on the linguistic processes of conceptualisation and classifications. Underneath language games is the biological level of instinctually based sign games, and under that, the cybernetic languaging game of the coordination of coordination of behaviour (of two black boxes). Thus, ecosemiotics also has a level of bio-psychological or emphatic signification, as well as a level of structural couplings, which the organism, or rather the species, has developed through evolution. Although the figure does not seem very simplified it is even more so, as it combines several simplified figures. But it functions as a tool to view the relations between the different levels of semiosis.

This is also true for the human species, indicating that our language has a deep inner connection to the ecology of our culture. Any existing culture is a collective way of making a social system survive ecologically. As such, the cybersemiotic theory of mind, perception and cognition is a realistic one, but not a materialistic or mechanistic one. It builds on an inner semiotic connection between living beings, nature, culture and consciousness carried by the three Peircian categories in a synechistic and tychastic ontology in an agapistic theory of evolution delivering a philosophy going beyond the dualistic oppositions between ideat ism (or spiritualism) and materialism (or mechanism).

Based on the concept relations in figure 5, we can go back and now see that the linguistic motivation, mentioned earlier, must be placed in the area of thought-semiotics where our internal non-linguistic phenosemiotic processes of mind meet with the concepts of language and imbue them with inner meaning, whereas the animal motivation stems from the intrasemiotic area where the endosemotic processes of the body cells meet with the phenosemiotic processes of mind and awareness. Thus body, mind and language has been encompassed by a shared framework able to conceptualise their interactions on the same process level but now integrating concepts of meaning and qualia.

The cybersemiotic model thus provides a new conceptual framework, in which these different levels of motivation can be represented and distinguished in a way that was not possibly in the earlier three different 
frameworks of biology, psychology and socio-culture. Thus, by viewing meaning in an evolutionary light, as always embodied, and seeing the body as semiotically organized in Peirce's triadic worldview, where mind as pure feeling is Firstness, a transdisciplinary framework can be constructed that supersedes some of the limitations of the earlier divisions of subject areas. This gives us hope that the cybersemiotic development of biosemiotics can contribute to a new inter- and transdisciplinary semiotic theory of mind, cognition, communication and consciousness.

\section{Conclusion}

I have now analysed the most prominent attempts of creating transdisciplinary frameworks for communication and cognition in physical nature, living nature, human culture, and in society as well as computers. They are all attempts to bridge the gap between Snow's two cultures, science-technology versus humanit ies and social sciences.

One major problem is how to place the mechanical, the living and the conscious system in relation to each other and how to fit this into the evolutionary framework of modern science. Another problem is how to find an all-encompassing unity without reducing one reality with another, making everything either phys ical, informational/computational, or semiotic.

Firstly, respecting the different nature of the physical, the informational and semiotical, how can we connect and understand the causal relations? Because we do not have a framework that integrates mind and matter, science today is not able to conceptualise how the conscious mind can causally influence the physiological processes in the body. Biosemiotic analysis of internal processing in the body (endosemiotics) and mind (phenosemiotics) in combination with systemic and cybernetic models of self-organization and closure (intrasemiotics) seems to offer an integrated approach to describing mind and bodily processes. Peircean semiotic philosophy seems to be able to deliver a philosophical and metaphysical framework without the limitations and flaws of the purely mechanical or informational approaches (including the computational information processing paradigm in cognitive science). It is now generally realized that the mechanical and the computational sciences can only describe limited and idealized aspects of reality. In both mechanical and the computational areas we can understand, control and predict systems with wonderful clarity and power. These systems, unfortunately, seem only to be tiny samples of the types of sys tems that make up the Universe as we know it. Recognizing that the social and psychological system of emotions, willpower and meaning are just as real as the mechanical system, although of a different nature, it is, no longer viable to model nature as pure mechanical or mind as only computational. On the basis of Peirce's philosophy, Cybersemiotic offers a different and more comprehensive foundation that encompasses the previously mentioned paradigms, but now relativized as being the most pertinent descriptions of certain levels of reality. They are parts of a greater whole where not only efficient causality (physical), but also formal causality (informational) and final (semiotic) causality work as real forces, but manifesting at different levels. The view, in short, is that semiosis is thus immanent in the universe and manifests clearly in the living systems and becomes emancipated and self-organized in social systems.

\section{References}

Bateson, Gregory (1973) Steps to an Ecology of Mind: collected essays in anthropology, psychiatry, evolution and epistemology. St. Albans. Paladin,

Blackmore, Susan (2000) The Meme Machine. Oxford. Oxford University Bress.

Bohm, David (1983) Wholeness and the Implicate order. New York. Routledge \& Kegan Paul Inc.

Brier, Søren (1992) Information and consciousness: A critique of the mechanistic concept of information. In: Cybernetics \& Human Knowing, Vol.1, No. 2/3, pp. 71-94.

Brier, Søren (1995) Cyber-semiotics: On autopoiesis, code-duality and sign games in bio-semiotics,. In: Cybernetics \& Human Knowing, Vol. 3, No. 1, pp.3-25.

Brier, Søren (1998a) The Cybersemiotic Explanation of the Emergence of Cognition: The Explanation of Cognition Signification and Communication in a Non-Cartesian Cognitive Biology. In: Evolution and Cognition, Vol. 4, No.1, pp. 90-105.

Brier, Søren (1998b) Cybersemiotics: a transdisciplinary framework for information studies, In: BioSystems, 46 (1998), pp. 185-191. 
Brier, Søren (1999a) On the Conflict between the Informational and the Semiotic Communicational Paradigm. In: Proceedings from the 43rd Annual Conference of The International Society for the Systems Sciences, 28. June - 2. July, Asilomar, Ca, USA. CDROM, Article No. 99169.

Brier, Søren (1999b) Biosemiotics and the foundation of cybersemiotics. Reconceptualizing the insights of Ethology, second order cybernetics and Peirce's semiotics in biosemiotics to create a non-Cartesian information science. In: Semiotica, Vol.127, No.1/4, pp.169-198. Special issue on Biosemiotics.

Brier, Søren (1999c) What is a possible ontological and epistemological framework for a true universal "Information science"? The suggestion of a cybersemiotics. In: Hofkirchner, Wolfgang (Ed.) (1999) The quest for a unified theory of Information: Proceedings of the 2nd International Conference on the Foundations of Information Science, 1996, Vienna, Austria. Amsterdam. Gordon \& Breach, pp. 79-99.

Brier, Søren (2000a) On the connection between cognitive semantics and ethological concepts of motivation: A possible bridge between embodiment in cognitive semantics and the motivation concept in ethology. In: Cybernetics and Human Knowing, Vol. 7. No. 1, pp. 57-75.

Brier, Søren (2000b) The relation between the semiotic and the informational research programs in the quest for a united theory for information, cognition and communication", Proceedings from the $7^{\text {th }}$ International Congress of the International Association for Semiotic Studies/Association Internationale de Sémiotique (IASS-AIS): Sign Processes in Complex Systems, Dresden, University of Technology, October 6-11, 1999. In print.

Brier, Søren (2000c) Cybersemiotics As A Suggestion For FIS. In: Proceedings of The World Congress of the Systems Sciences And ISSS 2000, International Society for the Systems Sciences, $44^{\text {th }}$ Annual Meeting, July $16-22,2000$, Toronto, Ontario Canada. Article No. 20150 - CD-ROM.

Brier, Søren (2000d) Trans-Scientific Frameworks of Knowing: Complementarity Views of the Different Types of Human Knowledge". In: Yearbook Edition of Systems Research and Behavioral Science, V.17, No. 5, pp. 433-458.

Brier, Søren (2001a) Cybersemiotics and Umweltlehre. In: Semiotica. Special issue on Jakob von Uexküll, 134-1/4, 779-814.

Brier, Søren (2001b) Cybersemiotics, Biosemiotics and Ecosemiotics, In: Tarasti, F, (2001): IST congress paper, Nordic Baltic Summer Inst. For Semiotic and Structural Studies. Ecosemiotics: Studies in Environmental Semiosis, semiotics of Biocybernetic Bodies, Human/too Human/Posthuman. Part IV, June 12-21, 2001, in Imatra, Finland. pp. 7-26.

Brier, Søren (2001c) Ecosemiotic and Cybersemiotics. In: Sign System Studies, 29.7, pp. 107-120.

Brier, Søren (2004) Peirce's Panethestic Scientific Mysticism. Proceedings from Symposium on Peirce's religious writing. Denver, May 2003. Forthcoming.

Combs, Allan and Brier, Søren (2001) Signs, Information, and Consciousness. In: SYSTEMS - Journal of Transdisciplinary Systems Science, Vol. 5, Number 1 and 2, 2000; Polish Systems Society, Wroclaw, Poland. In print.

Dawkins, Richard (1989) The Selfish Gene. Oxford Paperbacks

Deacon, Terrence W. (1997) The Symbolic Species: The co-Evolution of Language and the Brain. New York. Norton.

Deeley, John (1990) Basics of Semiotics. Bloomington. Indiana University Press.

Deely, John (1997) How is the universe perfused with signs? In: Spinks, C. W./Deely, John (Eds.) Semiotics. Peter Lang. New York.

Deely, John (1997) Physiosemiosis and semiotics. In: In: Spinks, C. W./Deely, John (Eds.) Semiotics. Peter Lang. New York.

Deely, John (2001) Physiosemiosis in the semiotic spiral: A play of musement. International Colloquium "The Semiotic Threshold from Nature to Culture", University of Kassel, Feb. 16-17.

Ellis, Ralph D./Newton, Nakita (1998) Three Paradoxes of Phenomenal Consciousness: Bridging the Explanatory Gap. In: Journal of Consciousness Studies, Vol. 5, No. 4, pp. 419-42.

Emmeche, Claus (2000). Transdisciplinarity, theory-zapping and the growth of knowledge. In: Semiotica, 131-3/4, 217-228.

Kirkeby, O.F. (1997) Event and body-mind. An outline of a Post-postmodern Approach to Phenomenology. In: Cybernetics \& Human Knowing, Vol. 4, No. 2/3, pp. 3-34.

Goerner, Sally J. (1993) Chaos and the Evolving Ecological Universe, The World Future General Evolution Studies, Vol. 7. Luxembourg. Gordon and Breach.

Hoffmeyer, Jesper (1998). Surfaces Inside Surfaces. In: Cybernetics \& Human Knowing, Vol. 5, No. 1, pp. $33-42$.

Jantsch, Erich (1980) The Self-Organizing Universe. New York. Pergamon Pres.

Lakoff, George (1987) Women, Fire and Dangerous Things: What Categories Reveal about the Mind, Chicago/London. The University of Chicago Press.

Lakoff, George and Johnson, Mark (1999) Philosophy in the flesh: The embodied mind and its challenge to western thought. New York. Basic Books.

Laszlo, Ervin (1995) The Interconnected Universe, Conceptual Foundations of Transdisciplinary Unified Theory. Singapore. World Scientific.

Luhmann, Niklas (1990) Essays on Self-Reference. New York. Colombia University Press.

Luhmann, Niklas (1995) Social Systems. Stanford, California. Stanford University Press.

Lorenz, Konrad (1970/71) Studies in animal and human behaviour I and II. Cambridge, Mass. Harvard University Press.

Lorenz, Konrad (1973) Die Rückseite des Spiegels: Versuch einer Naturgeschichte menschlichen Erkennens. München. Piper.

MacKay, Donald M. (1969) Information, Mechanism and Meaning. Cambridge, MA. MIT Press. 
Marijuán, Pedro C. (1998) Foreword: Foundations of Information Science. In: Cybernetics \& Human Knowing, Vol. 5, No.4. p. 2.

Maturana, Humberto R. (2000) The Nature of the Laws of Nature. In: Yearbook Edition of Systems Research and Behavioral Science, Systems Research, Vol. 17, No. 5, pp.459-468.

Maturana, Humberto R./Varela, Francisco J. (1980). Autopoiesis and Cognition: The realization of the Living. London. Reidel.

Merell, Floyd (1996) Signs grow: Semiosis of Life processes. Toronto. University of Toronto Press.

Nöth, Winfried (1995) Handbook of Semiotics. Bloomington and Indianapolis. Indiana University Press.

Nöth, Winfried (2001) Introduction to Ecosemiosis, Tarasti, ISI Congress papers, Nordic Baltic Summer Institute for Semiotic and Structural Studies Part IV, June 12-21 2001 in Imatra, Finland: Ecosemiotics: Studies in Environmental Semiosis, Semiotics of the Biocybernetic Bodies, Human/too Human/ Post Human, pp. 107-123.

Nöth, Winfried (2002) Semiotic machines. In: Cybernetics \& Human Knowing, Vol. 9, No. 1, pp. 5-21.

Ort, Nina/Marcus, Peter (1999) Niklas Luhmann: Sign as Form - A Comment. In: Cybernetics \& Human Knowing, Vol. 6, No. 3, pp. 39-46.

Peirce, Charles S. (1931-58). Collected Papers Vol. I-VIII. (eds.) Hartshorne and Weiss. Cambridge, Mass. Harvard University Press.

Peirce, C.S. (1992) The Essential Peirce: Selected Philosophical, Volume 1 (1867-1893). (Eds.) Houser, N. and Kloesel, C.. Bloomington. Indiana University Press.

Penrose, Roger (1995) Shadows of the Mind: A Search for the Missing Science of Consciousness. London. Oxford University Press. Prigogine, Ilya and Stengers, Isabelle (1984). Order Out of Chaos: Man's New Dialogue with Nature. New York. Bantam Books.

Ruesch, Jürgen/Bateson, Gregory (1987) Communication: The social matrix of psychiatry. New York. Norton Cop. (Orig. 1967)

Santaella Braga, Lucia (1999) Peirce and Biology. In: Semiotica Vol. 127, 1/4, Special Issue: Biosemiotica, pp. 5-21.

Schrödinger, Erwin (1967. What is life? The physical aspect of the living cell and mind and matter. Cambridge. Cambridge University Press. (Original 1942).

Sebeok, Thomas A. (1976) Contributions to the Doctrine of Signs. Bloomington. Indiana University Press, 1976.

Sebeok, Thomas A. (1989) The Sign \& Its Masters. Sources in Semiotics VIII. New York. University Press of America.

Shannon, Claude E./Weaver, Warren (1949) The mathematical theory of communication. Urbana, ILL. University of Illinois Press.

Stonier, Tom (1997) Information and Meaning: An Evolutionary Perspective. Berlin. Springer.

Uexküll, Jakob von (1934) A Stroll Through the Worlds of Animals and Men. A Picture Book of Invisible Worlds. In Schiller, Claire H.

(Ed.) (1957) Instinctive Behavior. The Development of a Modern Concept. New York. International Universities Press. pp. 5-80.

Uexküll, Thure von/Geigges, Werner/Herrmann Jörg M. (1993). Endosemiosis. In: Semiotica, 96 (1/2), pp. 5-51.

Wiener, Norbert (1961) Cybernetics or Control and Communication in the Animal and the Machine. New York. MIT Press and John Wiley \& Sons, Sec. Ed. (org. 1948).

Winograd, Terry/Flores, Fernando (1987) Understanding Computers and Cognition. Norwood, NJ. Alex Publishing Corporation Wittgenstein, Ludwig (1958) Philosophical Investigation, Third edition, translated by G.E.M. Anscombe. New York. Mac Millian. 